Seabright, M. (1971). Rapid banding technique for human chrosomes. Lancet, 2, 971-972.

Summitt, R. L. (1969). Cytogene ics in mentally defective children with anomalies: a controlled study. Fournal of Pediatrics, 74, 5866.

Talvik, T. A. and Mikelsaar, A.-V. N. (1969). A new case of ring chromosome of the group 21-22 ( $\mathrm{G}_{2}$ ?). Genetika, 5, No. 12 129-133.

Thorburn, M. J. and Johnson, B. E. (1966). Apparent monosomy of $\mathrm{G}$ autosome in Jamaican infant. Fourna! of Medical Genetics, 3, 290-292.

Weleber, R. G., Hecht, F., and Giblett, E. R. (1968). Ring-G chromosome, a new G-deletion sundrome? American fournal of Diseases of Children, 115, 489-493.

Zdansky, R., Bühler, E. M., Vest, M., Bühler, U. K., and Stalder, G. (1969). Familiäres Mosaik mit G-Ring. Humangenetik, 7, 275286.

\title{
An Autosomal Recessive Form of Craniofacial Dysostosis (The Crouzon Syndrome)
}

\begin{abstract}
Summary. Craniofacial dysostosis, the Crouzon syndrome, occurs sporadically and in families; the clearly heritable form up to now has been autosomal dominant. We ascertained two similarly affected sibs, a brother and a sister, in a sibship of nine. Neither the Negro parents nor any ancestors nor collateral relatives were similarly affected. The parents were not consanguineous. After excluding other genetic and environmental explanations, we concluded that the reasonably typical findings of the disorder in the two sibs were probably genetically determined by a single, autosomal recessive gene.
\end{abstract}

Craniofacial dysostosis, or the Crouzon syndrome after its describer, generally results in the following phenotype: cranial synostosis or synostoses, bilateral exophthalmos with external strabismus, psitticorhina, and maxillary underdevelopment with relative mandibular prognathism and a drooping lower lip. From the time of the original description most observers have recognized the syndrome to be genetically determined-specifically, monogenically as autosomal dominant-and they have usually

Received 4 April 1972. attributed sporadic cases to spontaneous mutation. Most authors have ascribed the frequent variability in the manifestations to irregular expression rather than to anomaly of penetrance.

Our purpose in this report is the description of two sibs, a female and a male, with manifestations of the syndrome; however, neither the parents nor the grandparents nor any consanguineous relatives have a similar appearance. After evaluating other explanations, we propose that the craniofacial disorder in the family is monogenically determined as autosomal recessive.

\section{Case Reports}

The sister of the propositus (Fig. 1) was born on 31 October 1961 and was first referred to the Confederate Memorial Medical Center of Shreveport, Louisiana, at the age of 9 months, because in treating her respiratory symptoms, the family physician noted a prominent anterior fontanelle. Results of the examination of her spinal fluid were normal, and she was treated for bilateral otitis media, the examiners noting no morphological abnormalities. Though the anterior fontanelle bulged on subsequent examinations at 10,12 , and 14 months, she was asymptomatic. She had two examinations in the clinic during the following year, and the anterior fontanelle bulged on each occasion.

At 28 months of age she showed rotatory nystagmus, exophthalmos, and visual defects. Skull radiology showed closed sutures and prominence in the region of the anterior fontanelle. Ventriculograms, made by trephining, demonstrated no abnormalities; but, three months later, her scalp still bulged at the operative sites.

She did not return for examination in our hospital until 9 years of age following the determination of visual difficulty in school. Her height of $132 \mathrm{~cm}$ placed her between the 25th and 50th centiles. By this time she manifested scaphocephaly with a slightly ridged sagittal suture; there was also bilateral prominence of the frontal bones (Fig. 2). She had a parrot-beaked nose and a relatively underdeveloped maxilla with a prominent mandible and a drooping lower lip (Fig. 3). Though she appeared to have somewhat shallow orbits and prominent globes, she did not have exophthalmos by measurement. Table I lists pertinent determinations, including her diminished visual acuity presumably from partial optic atrophy; from the cranial and intercanthal measurements we calculated her canthal index to be $\mathbf{4 3}$ and her circumference-interorbital index to be 8.3 (Gorlin and Pindborg, 1964). She continued to have rotatory nystagmus. She had no other significant abnormalities: specifically, her ear canals were normal, her nasal septum deviated slightly to the left, and her palate, uvula, and tongue were normal; she had 10 maxillary teeth, missing both canines, and 11 mandibular teeth, missing one first molar; her hands and feet were normal.

Skull radiology at 9 years displayed anterior flattening of the frontal bones and heavy convolutional markings, 


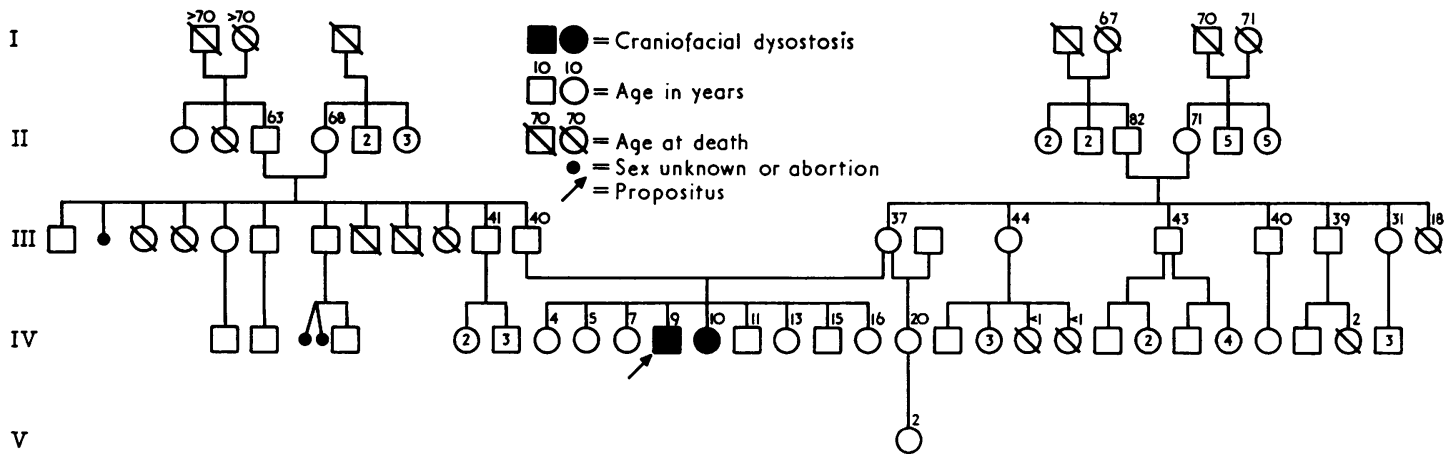

FIG. 1. Pedigree of the family.

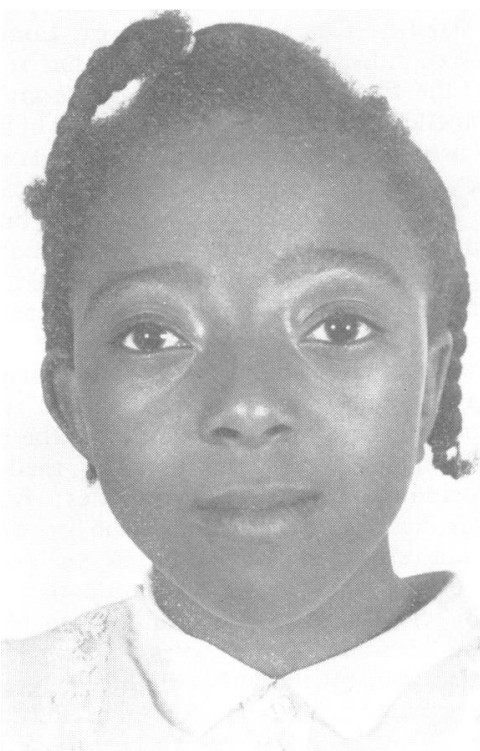

FIg. 2. Female sib at $9 \xi$ years with craniofacial dysostosis; note external strabismus.

presumably the result of increased intracranial pressure of several years' duration; sutural lines were not visible.

She completed the third grade of elementary school before placement in a special class for the retarded. Formal psychological evaluation classified her at firstgrade level in language arts and numbers skills. The test judged her retarded in articulation, vision, reading, and numbers skills-and very retarded in social skills. In addition to the difficulties mentioned above, she had chronic and recurrent otitis media resulting in moderate conductive hearing loss, and she received treatment by
FIG. 3. Female sib at $9 \frac{2}{3}$ years with craniofacial dysostosis; parrotbeaked nose, maxillary underdevelopment with mandibular prognathism and a drooping lower lip.

tonsillectomy, adenoidectomy, and provision of middle ear-drainage. She had no convulsions.

The propositus (see Fig. 1) was born on 23 March 1963, the sixth in a sibship of six females and three males; in addition, their mother had one daughter by a previous husband. At birth the weight of the propositus was $3.5 \mathrm{~kg}$, his height was $49 \mathrm{~cm}$, and his head circumference was $35 \mathrm{~cm}$.

He came to our hospital at $7 \frac{1}{2}$ years of age following a diagnosis of visual impairment from partial optic atrophy. His height of $124 \mathrm{~cm}$ placed him between the 
TABLE I

PHYSICAL MEASUREMENTS OF TWO SIBS WITH CRANIOFACIAL DYSOSTOSIS

\begin{tabular}{|c|c|c|}
\hline \multirow{2}{*}{ Measurement } & \multicolumn{2}{|c|}{ Affected Sib } \\
\hline & Female & Male \\
\hline $\begin{array}{l}\text { Circumference, cranial } \\
(\mathrm{cm})\end{array}$ & $51 \cdot 7$ & $50 \cdot 1$ \\
\hline \multirow{2}{*}{$\begin{array}{l}\text { Intercanthal, external } \\
\text { (cm) } \\
\text { Intercanthal, internal } \\
(\mathrm{cm})\end{array}$} & $10 \cdot 1$ & $9 \cdot 5$ \\
\hline & $4 \cdot 3$ & 3.9 \\
\hline Interpupillary $(\mathrm{cm})$ & $8 \cdot 5$ & $7 \cdot 3$ \\
\hline $\begin{array}{l}\text { Diameter, cornea (mm) } \\
\text { Left } \\
\text { Right }\end{array}$ & $\begin{array}{l}12 \\
12\end{array}$ & $\begin{array}{l}12 \\
12\end{array}$ \\
\hline $\begin{array}{l}\text { Exophthalmometry, } \\
\text { Hertel (mm) } \\
\text { Left } \\
\text { Right }\end{array}$ & $\begin{array}{l}19 \\
19\end{array}$ & $\begin{array}{l}16 \\
16\end{array}$ \\
\hline $\begin{array}{l}\text { Acuity, visual (corrected) } \\
\text { Left } \\
\text { Right }\end{array}$ & $\begin{array}{c}20 / 20 \\
\text { Light perception }\end{array}$ & $\begin{array}{l}20 / 20 \\
20 / 200\end{array}$ \\
\hline $\begin{array}{l}\text { Refraction } \\
\text { Left } \\
\text { Right }\end{array}$ & $\begin{array}{l}+1.00+1.25 \times 110 \\
+0.50+0.50 \times 135^{\circ}\end{array}$ & $\begin{array}{l}+0.25+0.25 \times 90^{2} \\
+0.50+0.25 \times 90^{3}\end{array}$ \\
\hline
\end{tabular}

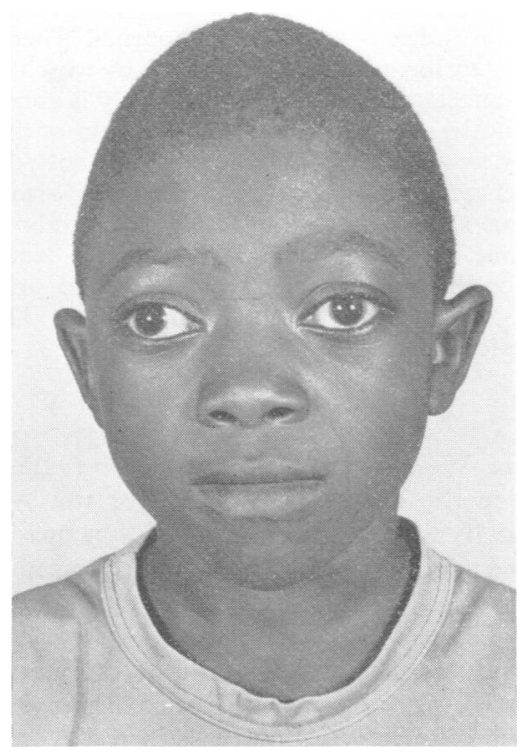

Frg. 4. Male sib at $8 \frac{1}{4}$ years with craniofacial dysostosis; note scaphocephaly and external strabismus. 25th and 50th centiles. He manifested scaphocephaly with prominence of the ridged sagittal suture and frontal bones (Fig. 4). Though he appeared to have prominent eyes, perhaps accentuated by strabismus, with somewhat shallow orbits, measurement did not indicate exophthalmos (Table I). Apparently less affected than his sister, his profile was not unusual (Fig. 5), so that his nose was not abnormal, and his maxilla and mandible were not disproportionate. His canthal index was estimated to be 41 and his circumference-interorbital index to be $7 \cdot 8$, both less than his sister's values. Like his sib, his ear canals were normal, his nasal septum deviated slightly to the left, and his palate, uvula, and tongue were normal. He had 10 maxillary teeth, missing both lateral incisors, and 12 mandibular teeth. His hands and feet were normal; he did not have convulsions.

Skull radiology exhibited heavy convolutional markings and absence of sutural lines. He completed the second grade of elementary school; however, formal psychological testing placed him as first-grade level in language arts and numbers skills and found him below average in learning capacity with poor visual perception, poor emotional control, and inadequate social adjustment.

By history there were no similarly affected persons on either side of the family (Fig. 1). One maternal aunt was reportedly crippled from the time of birth and died at 18 years. Two sisters, maternal first cousins of the propositus, died of unknown causes, each at less than 2 years of age, and another maternal first cousin died at age 2 from infectious disease. Neither of the two sibs nor their parents had either cranial or facial anomalies

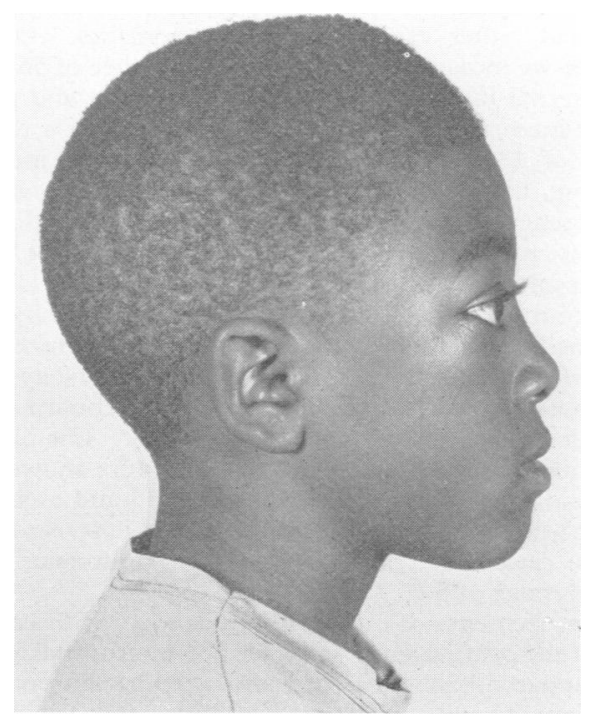

FIG. 5. Male sib at $8 \frac{1}{4}$ years with craniofacial dysostosis; normal profile. 


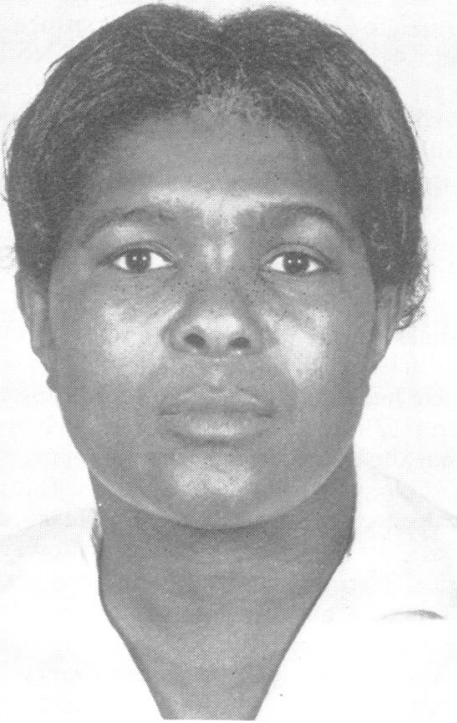

Fig. 6. Mother of the two offspring with craniofacial dysostosis (36 3 years).

according to our informants. The father's sibship had an unusual number of deceased persons; we determined only that one died with pneumonia and another with an enlarged heart. There was no consanguinity in the pedigree.

By examination neither the parents nor two younger sibs had either cranial or facial anomalies. On the mother we measured a cranial circumference of $56.5 \mathrm{~cm}$, an external intercanthal distance of $9.4 \mathrm{~cm}$, and an internal intercanthal distance of $4.0 \mathrm{~cm}$, giving a canthal index of 43 and a circumference-interorbital index of $7 \cdot 1$ (Fig. 6). On the father we measured a cranial circumference of $56 \mathrm{~cm}$, an external intercanthal distance of $10.0 \mathrm{~cm}$, and an internal intercanthal distance of 4.2 $\mathrm{cm}$, resulting in a canthal index of 42 and a circumference-interorbital index of 7.5; he actually had minimally pronounced frontal regions and a discernible sagittal suture (Fig. 7). However, skull radiology in the father as well as in the mother revealed no abnormalities, and the sutural lines were still visible. Calculations from measurements of two younger sisters showed the 5-year-old to have a canthal index of 35 and a circumference-interorbital index of 5.5, and the 4-year-old to have a canthal index of 38 and a circumference-interorbital index of $5 \cdot 7$.

Measurements of intercanthal distances with calculation of the canthal and circumference-interorbital indices have apparently not been previously reported for patients with craniofacial dysostosis. Unfortunately, standards for Negroes have not been published, though normal values for Caucasians have (C. T. Coccia, cited by

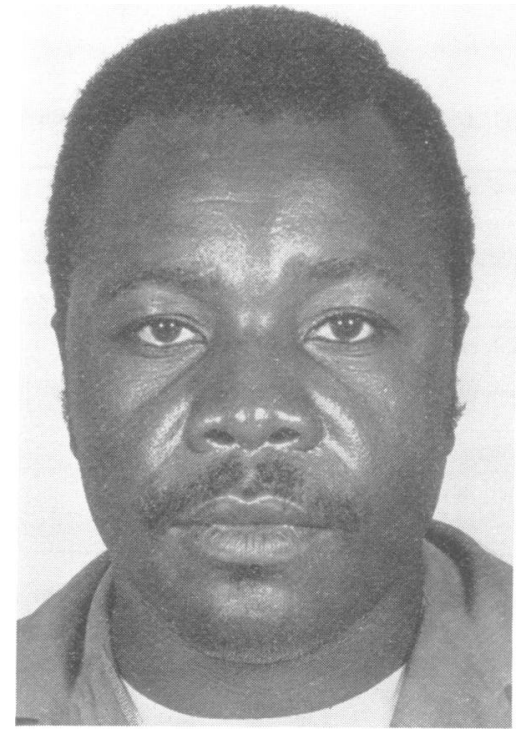

FIG. 7. Father of the two offspring with craniofacial dysostosis (39 years).

Christian et al, 1969). According to one definition of telecanthus in Caucasians-that is, a canthal index greater than 39.3 (Christian et al, 1969)-both sibs have telecanthus, but then so do their parents; the two younger sibs we measured do not. The circumferenceinterorbital index is said to be abnormal when greater than 8.0 (Gorlin and Pindborg, 1964), by which criterion only the affected female sib in this family is abnormal.

We studied excellent frontal photographs of the face of the other five full sibs and concluded not only that none exhibited cranial or facial abnormalities but also that the propositus and his sister both had a distinctly different appearance. The following blood groups were determined for the parents and the two affected sibs: ABO, Rhesus, MNSs, Duffy, Kell, Kidd, and P. There was no evidence for paternal exclusion.

\section{Discussion}

Dodge, Wood, and Kennedy (1959) reviewed and illustrated the diagnostic criteria for the syndrome as originally listed by Crouzon: (1) synostosis of one or more cranial sutures, (2) prognathism and parrot-beaked nose, (3) exophthalmos plus external strabismus, and (4) hereditary occurrence. Though possibly acceptable at the time of the description, the fourth criterion needs more definition today and, in fact, is relatively meaningless in the event of lack of penetrance, spontaneous mutation, extramarital paternity, phenocopy, variable expressivity, or an 
alternate form of inheritance, which is particularly relevant to the present report.

In this family, the female sib rather convincingly showed the cranial, facial, and ocular anomalies of the syndrome and, even without regard to the family history, she is properly placed in this diagnostic category. The propositus does not have as many abnormalities, particularly of the face, as his sister; yet we considered him to be affected because of his cranial deformity, his ocular defect, and the likeness to his sister combined with unlikeness to his sibs. Unfortunately, the family did not have enough pictures of either sib at appropriate intervals so that we might study the evolution of the anomalous development, but the propositus may show facial signs of the syndrome with advancing age; he is 17 months younger than his sister.

Apparently, considerable variation exists in the expression of the dominant gene for craniofacial dysostosis. For instance, sporadic cases with disfiguring cranial and facial abnormalities (Dodge $e t$ al, 1959) can be readily diagnosed, but cases that resemble other mildly affected members of the family, particularly when normal functions are maintained, may not be so apparent. The family reported by Vulliamy and Normandale (1966) illustrated how a family can accept some unusual appearance, because the presence of cranial and facial abnormality was unrecognized by the family in which the defect did not compromise the average lifespan and did not result in much disability. Shiller (1959) reported considerable variation in four generations of a family in which, probably coincidentally, the oldest affected persons were the least deformed and the youngest affected members were the most malformed.

We propose to explain the occurrence of the two similarly affected sibs, whose parents appear to be normal, by genetic determination, specifically by a single gene which is autosomal and recessive. First, we believe that each sib is abnormal; and, secondly, we conclude that they are similarly abnormal. Thirdly, we consider and dismiss the following explanations: (1) recurrent mutation at the autosomal locus where a dominant gene for craniofacial dysostosis is recognized, because of the improbability of this event, which is of the order of $\left(10^{-5}\right)^{2}$. (2) Lack of penetrance in one of the parents, because neither the grandparents nor any relatives are similarly affected and, less convincingly, because we know of no evidence that the dominant gene may be impenetrant. (3) Variable expressivity, because of the lack of any evidence that either parent is affected. (4) Extra-marital parentage, because of the failure to show exclusion by the blood group data. (5) Phenocopy, because we did not discover by history any suspicious environmental agents and, again, less securely, because we are unaware that such an aetiology has ever been reported. If our explanation is correct, the effect of the recessive gene in this family is certainly similar to the effect of the dominant gene already recognized.

Franceschetti (1953) suggested the term 'pseudoCrouzon' in order to classify two patients with cranial anomalies, which resembled those in acrocephaly and the Crouzon syndrome, but who had no facial disfigurement. The clinical and radiological features of the crania of his patients were like those in the usual craniofacial syndrome, but the patients lacked the ocular, nasal, maxillary, and mandibular defects; instead, they had a high forehead, a rather snub nose, and superior prognathism. The two sibs we have described do not have this phenotype, and we could not apply the term 'pseudo-Crouzon' to them. A classification with brief description of cranial abnormalities clearly separated 'hereditary craniofacial dysostosis (Crouzon's disease)' from other dysostoses of the cranial bones (Pinkerton and Pinkerton, 1952).

An autosomal recessive form of craniofacial dysostosis may have occurred previously; it simply has not been recognized as such in, for example, some of the sporadic cases without affected offspring. In addition, Flippen (1950) mentioned recessive determination as a theoretical consideration, and Hilson (1947) reported scaphocephaly in a brother and a sister.

Richard C. Juberg and Sue R. Chambers

Birth Defects Center, Department of Pediatrics, Louisiana State University School of Medicine in Shreveport, PO Box 3932, Shreveport, Louisiana 71130, USA

\section{REFERENCES}

Christian, J. C., Bixler, D., Blythe, S. C., and Merritt, A. D. (1969). Familial telecanthus with associated congenital anomalies. Birth Defects: Original Article Series, 5, pt. 2, pp. 82-85. National Foundation-March of Dimes, New York.

Dodge, H. W., Jr., Wood, M. W., and Kennedy, R. L. J. (1959). Craniofacial dysostosis: Crouzon's disease. Pediatrics, 23, 98-106.

Flippen, J. H., Jr. (1950). Cranio-facial dysostosis of Crouzon. Report of a case in which the malformation occurred in four generations. Pediatrics, 5, 90-96.

Franceschetti, A. (1953). Dysostose cranienne avec calotte cérébriforme (Pseudo-Crouzon). Confinia Neurologica, 13, 161-166.

Gorlin, R. J. and Pindborg, J. J. (1964). Syndromes of the Head and Neck. McGraw-Hill, New York.

Hilson, D. (1947). Scaphocephaly in a brother and sister. An unusual incidence of this form of premature synostosis of the skull bones. Clinical Proceedings, 6, 64-70. 
Pinkerton, O. D. and Pinkerton, F. J. (1952). Hereditary craniofacial dysplasia. American fournal of Ophthalmology, 35, 500-506.

Shiller, J. G. (1959). Craniofacial dysostosis of Crouzon. A case report and pedigree with emphasis on heredity. Pediatrics, 23, 107-112.

Vulliamy, D. G. and Normandale, P. A. (1966). Cranio-facial dysostosis in a Dorset family. Archives of Disease in Childhood, 41, 375-382.

\section{Three Generations and Six Family Members with a $t(13 q 15 q)$ Chromosome*}

\begin{abstract}
Summary. A patient with the clinical features of trisomy 13 without prosencephalic defects and with a $46, \mathrm{XX}$, $15-, t(13 q 15 q)+$ karyotype is reported. The translocation chromosome was present in five other phenotypically normal family members and could be traced back to the maternal grandfather.
\end{abstract}

The $t(\mathrm{DqDq})$ Robertsonian translocation is one of the most common translocations that occurs in man (about 1:1000, Hamerton, 1971). Cohen (1971) has compiled 64 cases of $t(\mathrm{DqDq})$ individuals in whom the $\mathrm{D}$ group chromosomes composing the translocation have been identified by autoradiography. Forty-nine of the $t(D q D q)$ chromosomes involved numbers 13 and 14, while only six were $t(13 q 15 q)$, five $t(13 q 13 q)$, three $t(14 q 15 q)$, and one $t(15 q 15 q)$. This report presents a family with a $t(13 q 15 q)$ chromosome detected in six individuals and spanning three generations. The aberration was discovered when the patient described below was born and diagnosed as having trisomy $\mathrm{D}$.

\section{Case Report}

The proposita was a premature infant, birth weight $2170 \mathrm{~g}$, born to a 30-year-old gravida IV, para III, abortus I, whose prenatal course was unremarkable. Labour and spontaneous delivery were uncomplicated. There had been no history of drug intake, radiology, or illness in the mother throughout gestation. At birth (Fig. 1) the infant was noted to have an ulcerated area in midline of her scalp overlying a bony defect or third

Received 18 September 1972.

* This work was supported in part by a research grant (AM-02504) from the National Institute of Arthritis and Metabolic Diseases, US Public Health Service and by a grant from the Birth Defects Institute, New York State Department of Health, Albany, NY.

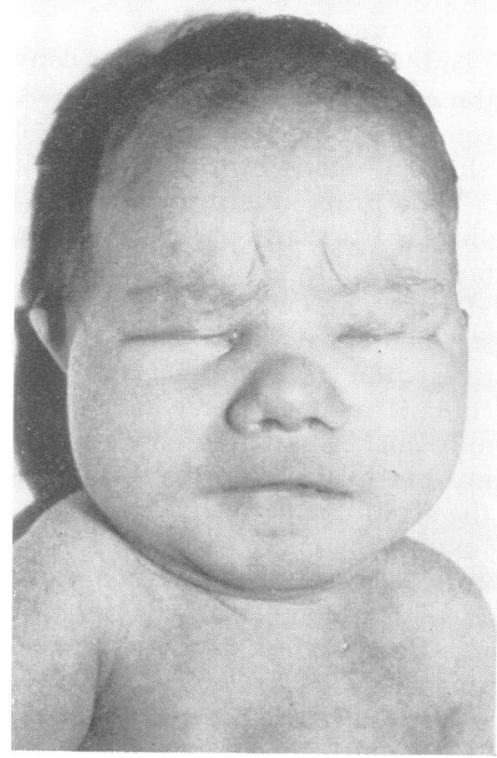

FIG. 1. Facies of patient at 5 days.

fontanelle, a slanted, small forehead with mild microcephaly, enophthalmos, and low set ears. There was a narrow chest with a grade II systolic murmur along the left sternal border, kidneys enlarged to palpation, poor muscle tone with complete head lag (the Moro reflex was normal), rocker-bottom feet, and bilateral simian creases. The laboratory data were non-remarkable.

Chest radiology revealed cardiomegaly but no increased pulmonary vasculature. Skull films showed some thinning of the parietal bone and thinning of the soft tissue overlying the thin portion of the parietal bone; the lumbosacral spine was normal. Radiology of the hips revealed flaring of both ilia with flattening of both acetabula; there was no dislocation. An intravenous pyelogram showed a normal collecting system in the left kidney without any evidence of obstruction. The right kidney did not opacify nor was a collecting system visualized.

The infant developed jaundice at 24 hours of age with a total bilirubin of $9.1 \mathrm{mg} \%(1.2 \mathrm{mg} \%$ direct bilirubin). The maximum value of bilirubin on the third day of life was $10.3 \mathrm{mg} \%$ (total) with a direct bilirubin of $1.3 \mathrm{mg} \%$. She had a generalized seizure within the first $\mathbf{4 8}$ hours of life associated with a low blood sugar ( $36 \mathrm{mg} \%)$ and normal serum calcium $(10 \cdot 2 \mathrm{mg} \%)$. Multiple seizures without hypoglycaemia occurred over the next six days but were then controlled with Dilantin and phenobarbital. Her condition remained stable until she again developed jaundice on the 22nd day of life. This was obstructive in character with a total bilirubin of $7.3 \mathrm{mg} \%$ and a direct bilirubin of $4.9 \mathrm{mg} \%$. The haematocrit decreased to $36 \%$ six days later. The baby also de- 